Author affiliations appear at the end of this article.

Published online ahead of print at www.jco.org on December 10, 2012

Supported by Millennium Pharmaceuticals, Janssen Research \& Development, and Janssen Global Services.

Presented as an oral presentation at the 2011 Annual Meeting of the American Society of Hematology, San Diego

CA, December 10-13, 2011.

Authors' disclosures of potential conflicts of interest and author contributions are found at the end of this article.

Clinical trial information: NCT00111319 Corresponding author: Jesús F. San Miguel, MD, Hospital Universitario Salamanca, Paseo San Vicente 58-182, 37007 Salamanca, Spain; e-mail: sanmigiz@usal.es.

(C) 2012 by American Society of Clinica Oncology

0732-183X/13/3104-448/\$20.00

DOI: 10.1200/JCO.2012.41.6180

\title{
Persistent Overall Survival Benefit and No Increased Risk of Second Malignancies With Bortezomib-Melphalan-Prednisone Versus Melphalan-Prednisone in Patients With Previously Untreated Multiple Myeloma
}

Jesús F. San Miguel, Rudolf Schlag, Nuriet K. Khuageva, Meletios A. Dimopoulos, Ofer Shpilberg, Martin Kropff, Ivan Spicka, Maria Teresa Petrucci, Antonio Palumbo, Olga S. Samoilova, Anna Dmoszynska, Kudrat M. Abdulkadyrov, Michel Delforge, Bin Jiang, Maria-Victoria Mateos, Kenneth C. Anderson, Dixie-Lee Esseltine, Kevin Liu, William Deraedt, Andrew Cakana, Helgi van de Velde, and Paul G. Richardson

$$
\begin{array}{llllllll}
\text { A } & \text { B } & \text { S } & \text { T } & \text { R } & \text { A } & \text { C } & \text { T }
\end{array}
$$

\section{Purpose}

This final analysis of the phase III VISTA trial (Velcade As Initial Standard Therapy in Multiple Myeloma: Assessment With Melphalan and Prednisone) was conducted to determine whether the overall survival (OS) benefit with bortezomib-melphalan-prednisone (VMP) versus melphalanprednisone (MP) in patients with myeloma who were ineligible for transplantation was maintained after 5 years of follow-up and to explore the risk of second primary malignancies.

\section{Patients and Methods}

In all, 682 patients received up to nine 6-week cycles of VMP or MP and were then observed every 12 weeks or less. Data on second primary malignancies were collected by individual patient inquiries at all sites from 655 patients.

\section{Results}

After median follow-up of 60.1 months (range, 0 to 74 months), there was a $31 \%$ reduced risk of death with VMP versus MP (hazard ratio [HR], 0.695; $P<.001$; median OS 56.4 v 43.1 months). OS benefit with VMP was seen across prespecified patient subgroups (age $\geq 75$ years, stage III myeloma, creatinine clearance $<60 \mathrm{~mL} / \mathrm{min}$ ). Sixty-three percent of VMP patients and $73 \%$ of MP patients had received subsequent therapy. Time to next therapy (median, $30.7 \vee 20.5$ months; HR, $0.557 ; P<.001$ ) was longer with VMP than with MP. Among patients who received subsequent therapies, survival from start of subsequent therapy was similar following VMP (median, 28.1 months) or MP (median, 26.8 months; HR, 0.914). Following VMP/MP, incidence proportions of hematologic malignancies $(1 \% / 1 \%)$ and solid tumors $(5 \% / 3 \%)$ and exposure-adjusted incidence rates $(0.017 / 0.013$ per patient-year) were similar and were consistent with background rates.

\section{Conclusion}

VMP resulted in a significant reduction in risk of death versus MP that was maintained after 5 years' follow-up and despite substantial use of novel-agent-based salvage therapies. There is no emerging safety signal for second primary malignancies following VMP.

\section{J Clin Oncol 31:448-455. (C) 2012 by American Society of Clinical Oncology}

\section{INTRODUCTION}

Prolonging overall survival (OS) remains the ultimate goal of treatment for multiple myeloma (MM) in the absence of curative therapy. ${ }^{1,2}$ However, particularly for regimens in the first-line setting, demonstrating improved OS is challenging because of the availability of multiple highly active treatment options for subsequent therapy on relapse or progression. ${ }^{3,4}$ Population-based analyses have demonstrated that median OS has improved over the past two decades, and it has been associated with the use of autologous stem-cell transplantation for younger patients and the use of novel agents such as bortezomib, thalidomide, and lenalidomide. ${ }^{5-9}$ Notably, some phase III trials in patients ineligible for transplantation ${ }^{10-20}$ have reported prolonged OS with regimens based on novel agents versus previous standards of care. ${ }^{13,14,19}$ A frequent criticism of studies showing positive results with experimental treatments is that data are preliminary, notably for OS. This is of particular relevance in MM, for which it could be argued that conventional, less-expensive first-line treatment followed by optimized rescue 
therapies may prove equivalent to the first-line use of novel regimens. Thus, confirmation of benefit after long-term follow-up is essential.

Another important issue is the risk of developing second primary malignancies because patients are living longer from time of diagnosis. ${ }^{21}$ Population studies ${ }^{22-25}$ and data from the National Cancer Institute's Surveillance, Epidemiology, and End Results (SEER) Program ${ }^{26}$ have shown that patients with MM have an increased risk of developing specific second primary malignancies following their initial diagnosis, most notably, acute myeloid leukemia, ${ }^{26}$ associated either with the disease itself or with the use of some specific agents. ${ }^{20,24,27-34}$ As demonstrated by SEER data, the risk of developing these malignancies may increase with time from diagnosis. ${ }^{26}$ Clearly, this issue is of increasing importance for patients with MM, particularly in the context of prolonged OS.

Per protocol, we conducted a final updated OS analysis of the international, phase III VISTA trial (Velcade As Initial Standard Therapy in Multiple Myeloma: Assessment With Melphalan and Prednisone) after a median follow-up of 5 years. VISTA compared efficacy and safety of bortezomib-melphalan-prednisone (VMP) with melphalan-prednisone (MP) in previously untreated patients with MM who were ineligible for transplantation. To the best of our knowledge, this report represents the longest median follow-up in phase III trials of novel agents in combination with MP in this population. ${ }^{10-}$ 18,20 Data from the initial analysis, with median follow-up of 16.3 months, showed that VMP was superior to MP across all efficacy end points, including response rates, time to progression (TTP), and OS. ${ }^{11}$ An updated analysis, with median follow-up of approximately 3 years, demonstrated a continued significant OS benefit with VMP. ${ }^{10}$ This final analysis was therefore conducted to determine whether the significant OS benefit was maintained after 5 years, after extensive use of subsequent therapies based on novel agents as salvage therapies, and to explore for the first time the risk of second primary malignancies with long-term use of bortezomib in VMP.

\section{PATIENTS AND METHODS}

\section{Patients and Study Design}

VISTA study details have been reported. ${ }^{10,11}$ Briefly, 682 patients with previously untreated $\mathrm{MM}$ who were ineligible for high-dose therapy were enrolled at 151 sites in 22 countries in Europe, North America, South America, and Asia. Eligible patients were age $\geq 18$ years and had symptomatic, measurable disease; exclusion criteria included grade $\geq 2$ peripheral neuropathy or neuropathic pain and a serum creatinine level of more than $2 \mathrm{mg} / \mathrm{dL}$. Review boards at all participating institutions approved the study, which was conducted according to International Conference on Harmonization Guidelines for Good Clinical Practice. All patients provided written informed consent.

Patients were randomly assigned 1:1 to receive nine 6-week cycles of $\operatorname{VMP}\left(\mathrm{n}=344\right.$; bortezomib $1.3 \mathrm{mg} / \mathrm{m}^{2}$ per day on days $1,4,8,11,22,25,29$, and 32 during cycles 1 to 4 and on days $1,8,22$, and 29 during cycles 5 to 9 , with melphalan $9 \mathrm{mg} / \mathrm{m}^{2}$ and prednisone $60 \mathrm{mg} / \mathrm{m}^{2}$ per day on days 1 through 4 of all cycles) or MP alone ( $\mathrm{n}=338)$. The primary end point was TTP. Secondary end points included response rates, OS, and safety/tolerability; additional end points included time to next therapy (TTNT; from random assignment to start of subsequent anti-MM treatment) and treatment-free interval (TFI; from the last dose of study drug to the start of subsequent treatment). Response and progression were assessed according to European Group for Blood and Bone Marrow Transplantation (EBMT) criteria $^{35}$ by using central laboratory M-protein assessment. Central laboratory assessment was stopped following the third preplanned interim analysis ${ }^{10,11}$; consequently response, TTP, and progression-free survival (PFS) data could not be updated beyond this initial report (median follow-up, 16.3 months) according to the same stringency because centralized M-protein assessment was no longer available.

Per protocol, patients were observed at least every 12 weeks for up to 4.5 years after the last-patient-in date for survival and subsequent therapy; data cutoff was March 24, 2011. Data on second primary malignancies were collected by individual patient inquiries at all study sites during February 2011 from 655 patients $(96 \%)$.

\section{Statistical Analysis}

OS was analyzed by using Kaplan-Meier methodology, and TTNT and TFI were analyzed by using cumulative incidence methodology. Data were compared between arms by using stratified log-rank tests, and hazard ratios (HRs) with 95\% CIs were calculated. OS was compared between arms and within arms in prespecified patient subgroups defined by age, sex, race, region, baseline $\beta_{2}$-microglobulin, baseline albumin, International Staging System (ISS) disease stage, ${ }^{36}$ and renal function. OS was also evaluated in patients with documented high-risk cytogenetics such as $\mathrm{t}(4 ; 14), \mathrm{t}(14 ; 16)$, and $\operatorname{del}(17 \mathrm{p})$. OS was compared according to best response (by EBMT criteria), overall and by treatment arm, by using multivariate Cox regression with time-dependent covariates that incorporated response, with adjustment for baseline $\beta_{2}$ microglobulin, baseline albumin, and region as stratification factors, plus age, sex, race, type of MM, baseline Karnofsky performance status, and number of bone lesions at baseline as covariates. OS and survival from start of subsequent therapy were also evaluated in patients who had received subsequent therapies, and OS was compared between all patients on the VMP arm and patients on the MP arm who had not yet relapsed, received salvage therapy with bortezomib, or died without receiving subsequent therapy.

For analyses of second primary malignancies, incidence proportions and exposure-adjusted incidence rates were calculated, plus relative risks and 95\% CIs. Exposure was defined as total duration of follow-up in each patient from start of treatment to the time of reporting occurrence of second primary malignancy. Incidence rate was calculated by dividing total number of second primary malignancies by duration of exposure in patient-years.

\section{RESULTS}

\section{Patients}

Baseline characteristics have been reported ${ }^{11}$ and were well balanced between treatment arms. Overall, median age was 71 years, 30\% of patients were age $\geq 75$ years, and $34 \%$ had ISS stage III MM. At data cutoff, only 16 patients (5\%) in each arm had been lost to follow-up (Fig 1).

\section{OS}

After a median follow-up of 5 years (60.1 months; range, 0 to 74 months) from random assignment, 176 patients (51\%) randomly assigned to VMP and 211 (62\%) randomly assigned to MP had died (Fig 1). There was a 31\% reduced risk of death following VMP versus MP (HR, 0.695; $P<.001$; Fig 2). Median OS was 56.4 versus 43.1 months; 5-year OS rates were $46.0 \%$ (95\% CI, $40.3 \%$ to $51.8 \%$ ) and $34.4 \%$ (95\% CI, $28.9 \%$ to $39.9 \%$ ), respectively.

The OS benefit with VMP was seen across prespecified patient subgroups, including those age $\geq 75$ years (median, $50.7 v 32.9$ months; HR, 0.70), those younger than 75 years (median, $58.6 v$ 47.7 months; HR, 0.69), patients with ISS stage III MM (median, 46.2 $v 30.5$ months; HR, 0.63), and those with creatinine clearance less than $60 \mathrm{~mL} / \mathrm{min}$ (median, 56.8 v 36.7 months; HR, 0.70; Fig 3). However, no significant difference was observed in the small subgroup with documented high-risk cytogenetics ( $n=46$; Fig 3 ); because of low patient numbers, additional analyses by individual cytogenetic abnormalities were not feasible. 


\begin{tabular}{|c|c|c|c|}
\hline & \multicolumn{2}{|c|}{$\begin{array}{l}\text { Assessed for eligibility } \\
\qquad(N=755)\end{array}$} & \\
\hline & & \multirow{2}{*}{$\begin{array}{c}\text { Excluded } \\
(n=73)\end{array}$} & \\
\hline & $\begin{array}{l}\text { Randomly allocated } \\
\qquad(\mathrm{n}=682)\end{array}$ & & \\
\hline $\begin{array}{l}\text { Allocated to bortezomib plus } \\
\text { melphalan-prednisone } \\
\text { Received treatment } \\
\text { Did not receive treatment } \\
\text { Patient choice } \\
\text { Other }\end{array}$ & $\begin{array}{l}(n=344) \\
(n=340) \\
(n=4) \\
(n=3) \\
(n=1)\end{array}$ & $\begin{array}{l}\text { Allocated to me } \\
\text { Received treatn } \\
\text { Did not receive } \\
\text { Adverse event }\end{array}$ & $\begin{array}{r}(n=338) \\
(n=337) \\
(n=1) \\
(n=1)\end{array}$ \\
\hline $\begin{array}{l}\text { Trial discontinued } \\
\text { Study closed by sponsor } \\
\text { Death } \\
\text { Patient choice } \\
\text { Lost to follow-up }\end{array}$ & $\begin{array}{r}(n=340) \\
(n=133) \\
(n=176) \\
(n=15) \\
(n=16)\end{array}$ & $\begin{array}{l}\text { Trial discontinu } \\
\text { Study closed } b \\
\text { Death } \\
\text { Patient choice } \\
\text { Lost to follow- }\end{array}$ & $\begin{array}{r}(n=337) \\
(n=95) \\
(n=211) \\
(n=15) \\
(n=16)\end{array}$ \\
\hline $\begin{array}{l}\text { Treatment completed } \\
\text { Discontinued treatment } \\
\text { Progressive disease } \\
\text { Adverse event } \\
\text { Patient choice } \\
\text { Death } \\
\text { Maintenance of complete response } \\
\text { Other }\end{array}$ & $\begin{array}{r}(n=199) \\
(n=141) \\
(n=24) \\
(n=52) \\
(n=32) \\
(n=14) \\
(n=9) \\
(n=10)\end{array}$ & $\begin{array}{l}\text { Treatment com } \\
\text { Discontinued tr } \\
\text { Progressive di } \\
\text { Adverse event } \\
\text { Patient choice } \\
\text { Death } \\
\text { Maintenance c } \\
\text { Other }\end{array}$ & $\begin{array}{r}(n=169) \\
(n=168) \\
(n=73) \\
(n=48) \\
(n=19) \\
(n=17) \\
(n=1) \\
(n=10)\end{array}$ \\
\hline $\begin{array}{l}\text { Analyzed for response } \\
\text { Excluded from response analysis } \\
\text { No measurable disease at baseline }\end{array}$ & $\begin{array}{r}(n=337) \\
(n=3) \\
(n=3)\end{array}$ & $\begin{array}{l}\text { Analyzed for re } \\
\text { Excluded from } \\
\text { No measurabl }\end{array}$ & $\begin{array}{r}(n=331) \\
(n=6) \\
(n=6)\end{array}$ \\
\hline $\begin{array}{l}\text { Analyzed for SPMs } \\
\text { Excluded from SPM analysis } \\
\text { Lost to follow-up }\end{array}$ & $\begin{array}{r}(n=327) \\
(n=13) \\
(n=13)\end{array}$ & $\begin{array}{l}\text { Analyzed for SP } \\
\text { Excluded from } \\
\text { Lost to follow- }\end{array}$ & $\begin{array}{r}(n=328) \\
(n=9) \\
(n=9)\end{array}$ \\
\hline $\begin{array}{l}\text { Received subsequent therapy } \\
\text { Did not receive subsequent therapy } \\
\text { Not yet required } \\
\text { Died due to PD prior to receiving } \\
\text { subsequent therapy }\end{array}$ & $\begin{array}{c}(n=215) \\
(n=129) \\
(n=120) \\
(n=9)\end{array}$ & $\begin{array}{l}\text { Received subse } \\
\text { Did not receive } \\
\text { Not yet requir } \\
\text { Died due to } P L \\
\text { subsequent } t\end{array}$ & $\begin{array}{r}(\mathrm{n}=246) \\
(\mathrm{n}=92) \\
(\mathrm{n}=78) \\
\\
(\mathrm{n}=14)\end{array}$ \\
\hline
\end{tabular}

Fig 1. Updated CONSORT diagram showing patient flow through the study. PD, progressive disease; SPM, second primary malignancy.
Multivariate Cox regression analysis of OS according to best response demonstrated a clear impact of response on improved outcome. OS was significantly improved with complete response versus less-than-complete response by intent-to-treat analysis (HR, 0.675; 95\% CI, 0.486 to $0.936 ; P=.0184$; VMP arm: HR, 0.708; 95\% CI, 0.484 to $1.036 ; P=.0755$; MP arm: $\mathrm{HR}, 0.710 ; 95 \% \mathrm{CI}, 0.303$ to 1.662 ; $P=.4301)$. There was also a trend toward improved OS with complete versus partial response by intent-to-treat analysis (HR, 0.761; 95\% CI, 0.540 to $1.071 ; P=.1173)$.

\section{Subsequent Therapies and TTNT}

In all, 215 (63\%) of $344 \mathrm{VMP}$ and $246(73 \%)$ of $338 \mathrm{MP}$ patients had received subsequent anti-MM therapies. Use of subsequent tha- lidomide or lenalidomide was similar between arms, with 103 (30\%) of 344 VMP patients and $122(36 \%)$ of $338 \mathrm{MP}$ patients having received subsequent thalidomide and 84 (24\%) and 63 (19\%) subsequent lenalidomide (Appendix Table A1, online only). A lower proportion of VMP versus MP patients received subsequent bortezomib $(22 \%[n=77]$ versus $43 \%[n=145])$; this imbalance was also seen in the small subgroup of patients with high-risk cytogenetics (Appendix Table A1). Investigator-assessed response rates to subsequent bortezomib and/or bortezomib-containing regimens were $50 \%$ following VMP (ie, bortezomib re-treatment) and 58\% following MP, were 46\% and $55 \%$, respectively, to subsequent thalidomide and/or thalidomide-containing regimens, and were $62 \%$ and $56 \%$, respectively, to subsequent lenalidomide and/or lenalidomide-containing regimens. 


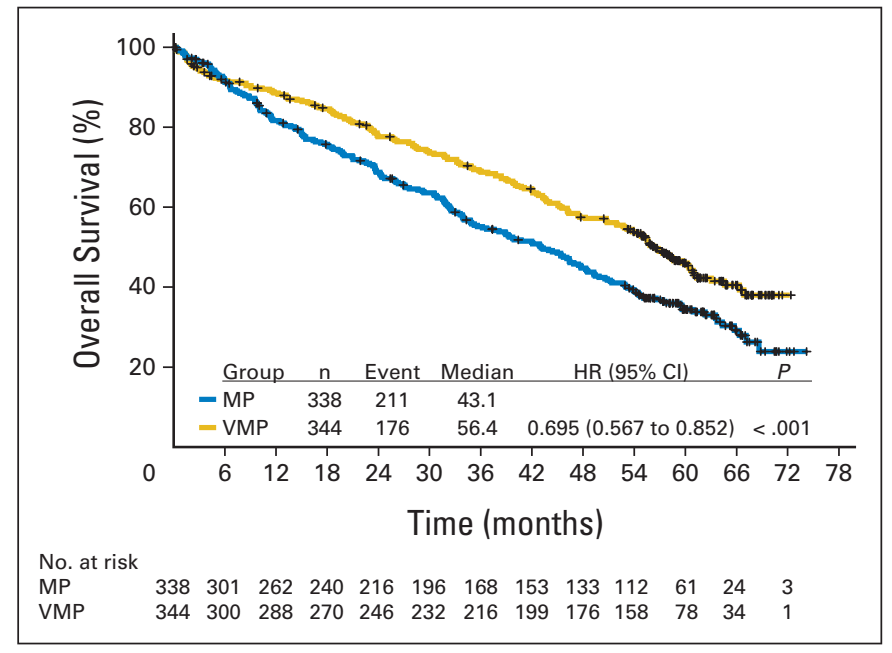

Fig 2. Overall survival (intent-to-treat analysis) in patients randomly assigned to bortezomib-melphalan-prednisone (VMP) or melphalan-prednisone (MP) after a median follow-up of 5 years. HR, hazard ratio.

Use of older agents was generally similar between arms (Appendix Table A1). TTNT (median, 30.7 v 20.5 months; HR, 0.557; $P<.001$ ) and TFI (median, $19.4 v 9.1$ months; HR, 0.573; $P<.001$ ) were longer with VMP versus MP by cumulative incidence analysis (Table 1).

To assess whether VMP induced more resistant relapses, we compared survival from start of subsequent therapy and showed that it was similar between arms (HR, 0.914; 95\% CI, 0.719 to 1.163; Fig 4). Moreover, to investigate the treatment paradigm of first-line MP followed by subsequent salvage bortezomib, we compared OS in all VMP patients with OS in MP patients who had received salvage therapy with bortezomib $(\mathrm{n}=145)$, not yet relapsed $(\mathrm{n}=78)$, or died without receiving subsequent therapy $(\mathrm{n}=14)$. Median OS was 56.4 versus 45.4 months, respectively ( $\mathrm{HR}, 0.714$; $95 \% \mathrm{CI}, 0.571$ to 0.892 ; $P=.0029)$. Similar results were observed in an analysis incorporating MP patients who received bortezomib at first relapse only (HR, 0.638; 95\% CI, 0.499 to $0.817 ; P<.001)$.

\section{Second Primary Malignancies}

In all, $327 \mathrm{VMP}$ patients (95\%) and $328 \mathrm{MP}$ patients (97\%) were included in the analyses of second primary malignancies (Table 2). Incidence proportions of all malignancies and of fatal hematologic malignancies and solid tumors were similar between arms (Table 2). Nineteen (6\%) of 327 patients in the VMP arm and 13 (4\%) of 328 patients in the MP arm reported second primary malignancies. Three patients $(1 \%)$ in each arm had hematologic malignancies: two patients in each arm had acute myeloid leukemia (fatal in all four patients), one patient in the MP arm had B-cell non-Hodgkin lymphoma that was fatal, and one patient in the VMP arm had myelodysplastic syndrome. In the VMP arm, these hematologic malignancies were reported at 18, 47.4 , and 48 months after the start of treatment; in the MP arm, the malignancies occurred at $1,8.8$, and 35 months. Sixteen patients $(5 \%)$ in the VMP arm and 10 patients (3\%) in the MP arm had second primary nonhematologic malignancies that were mostly gastrointestinal (five, VMP; four, MP) and renal or prostate (four, VMP; three, MP) tumors. These were fatal in six patients $(2 \%)$ in each arm. These malignancies occurred after a median of 22.7 months (range, 1 to 56

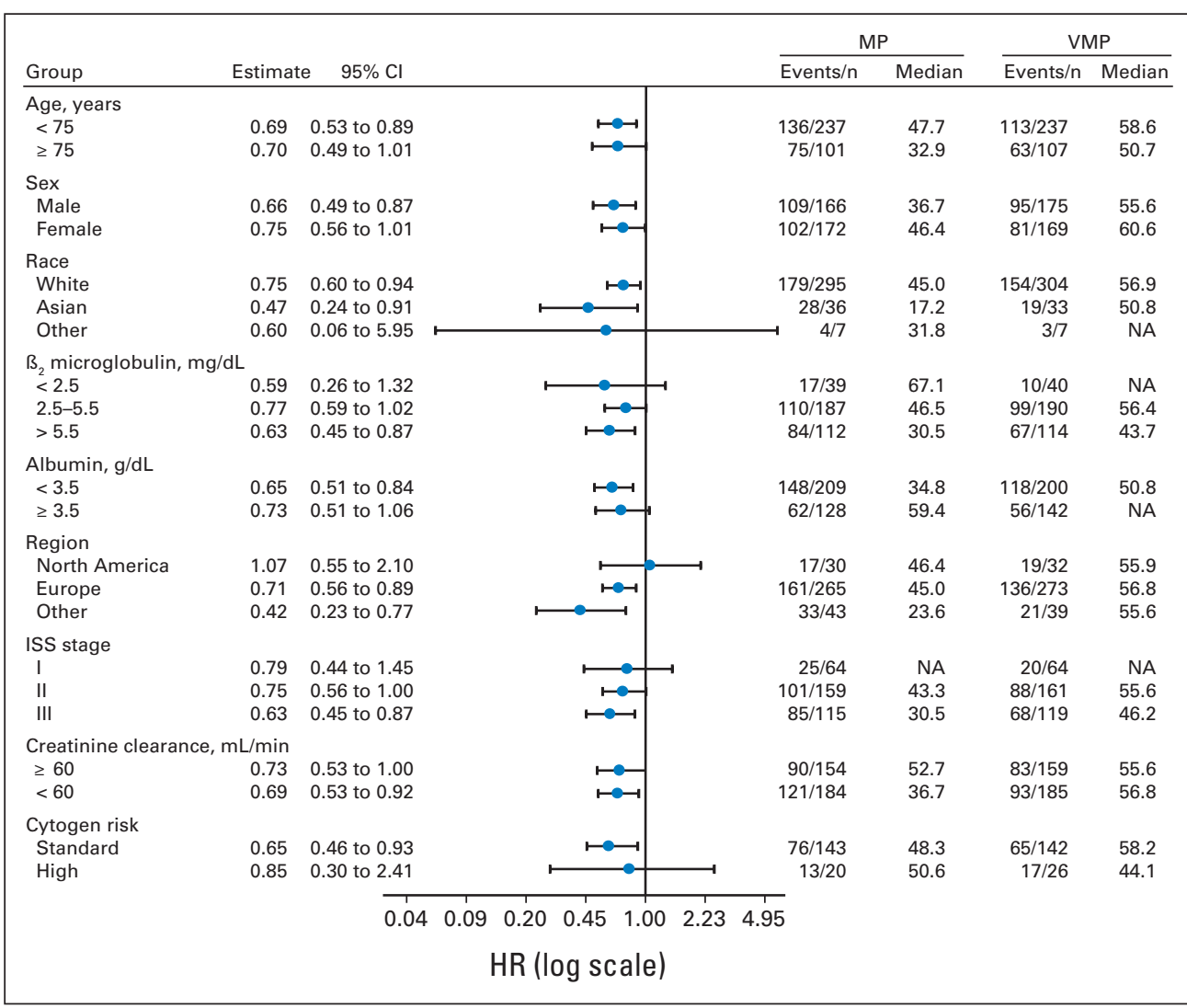

Fig 3. Subgroup analyses of overall survival. $P$ values for subgroup interaction tests were all nonsignificant (range, .1394 [region: other] to .9352 [age: $\geq 75$ years]). HR, hazard ratio; ISS, International Staging System; MP, melphalan-prednisone; NA, not assessable; VMP, bortezomib-melphalan-prednisone. 
Table 1. TTNT in Patients Randomly Assigned to VMP or MP and TFI in the Treated Population, Analyzed by Cumulative Incidence Using the Competing Risk Approach

\begin{tabular}{|c|c|c|c|c|c|c|c|c|c|c|c|c|c|c|c|c|}
\hline \multirow[b]{3}{*}{ Variable } & \multicolumn{8}{|c|}{ TTNT } & \multicolumn{8}{|c|}{ TFI } \\
\hline & \multicolumn{5}{|c|}{$\begin{array}{c}\text { VMP } \\
(n=344)\end{array}$} & \multicolumn{3}{|c|}{$\begin{array}{c}\text { MP } \\
(n=338)\end{array}$} & \multicolumn{5}{|c|}{$\begin{array}{c}\text { VMP } \\
(n=340)\end{array}$} & \multicolumn{3}{|c|}{$\begin{array}{c}\text { MP } \\
(n=337)\end{array}$} \\
\hline & No. & $\%$ & $\mathrm{HR}^{*}$ & $95 \% \mathrm{Cl}$ & $P+$ & No. & $\%$ & $95 \% \mathrm{Cl}$ & No. & $\%$ & $\mathrm{HR}^{*}$ & $95 \% \mathrm{Cl}$ & $P+$ & No. & $\%$ & $95 \% \mathrm{Cl}$ \\
\hline Events & 224 & 65 & & & & 260 & 77 & & 224 & 66 & & & & 260 & 77 & \\
\hline $\begin{array}{l}\text { Censored/competing } \\
\text { events }\end{array}$ & 120 & 35 & & & & 78 & 23 & & 116 & 34 & & & & 77 & 23 & \\
\hline $\begin{array}{l}\text { TTNT/TFI, months } \\
25 \% \text { quartileł } \\
50 \% \text { quartileł } \\
75 \% \text { quartileł }\end{array}$ & $\begin{array}{l}17.1 \\
30.7 \\
\text { N/E }\end{array}$ & & & & & $\begin{array}{l}10.0 \\
20.5 \\
34.8\end{array}$ & & & $\begin{array}{r}7.1 \\
19.4 \\
52.7\end{array}$ & & & & & $\begin{array}{r}2.2 \\
9.1 \\
24.1\end{array}$ & & \\
\hline $\begin{array}{l}\text { Event-free } \\
\text { survival rate } \neq\end{array}$ & & & 0.557 & 0.462 to 0.671 & $<.001$ & & & & & & 0.573 & 0.476 to 0.690 & $<.001$ & & & \\
\hline 1 year & & 85.1 & & 81.1 to 88.7 & & & 71.3 & 66.3 to 76.1 & & 62.0 & & 56.8 to 67.3 & & & 44.1 & 38.9 to 49.7 \\
\hline 2 year & & 60.5 & & 55.3 to 65.8 & & & 40.9 & 35.7 to 46.5 & & 46.3 & & 41.1 to 51.9 & & & 25.1 & 20.7 to 30.3 \\
\hline 3 year & & 45.2 & & 40.0 to 50.8 & & & 24.4 & 20.0 to 29.5 & & 36.1 & & 31.1 to 41.6 & & & 19.4 & 15.5 to 24.2 \\
\hline 4 year & & 35.7 & & 30.7 to 41.2 & & & 19.6 & 15.6 to 24.5 & & 30.9 & & 26.0 to 36.5 & & & 18.1 & 14.2 to 22.9 \\
\hline 5 year & & 31.5 & & 26.6 to 37.0 & & & 18.3 & 14.4 to 23.2 & & 25.9 & & 20.4 to 32.4 & & & 15.6 & 10.5 to 22.9 \\
\hline
\end{tabular}

Abbreviations: HR, hazard ratio; MP, melphalan-prednisone; N/E, not estimable; TFI, treatment-free interval; TTNT, time to next therapy; VMP, bortezomibmelphalan-prednisone.

*Based on the cause-specific hazard.

tBased on a stratified log-rank test comparing cause-specific hazards for subsequent treatment.

$\neq$ Based on cumulative incidence estimates.

months) in the VMP arm and 30.3 months (range, 3 to 63 months) in the MP arm.

The overall observation or exposure period for recording occurrence of second primary malignancies was asymmetric, being longer in the VMP arm compared with the MP arm because more patients remained alive for a longer period on that arm. Exposure in the VMP arm was greater than in the MP arm by 163 patient-years $(1,167 v$ 1,004 patient-years, respectively; Table 2). The exposure-adjusted incidence rates for all second primary malignancies, which take into account this longer observation period, were similar between arms ( 0.0166 and 0.013 per patient-year for VMP and MP, respectively).

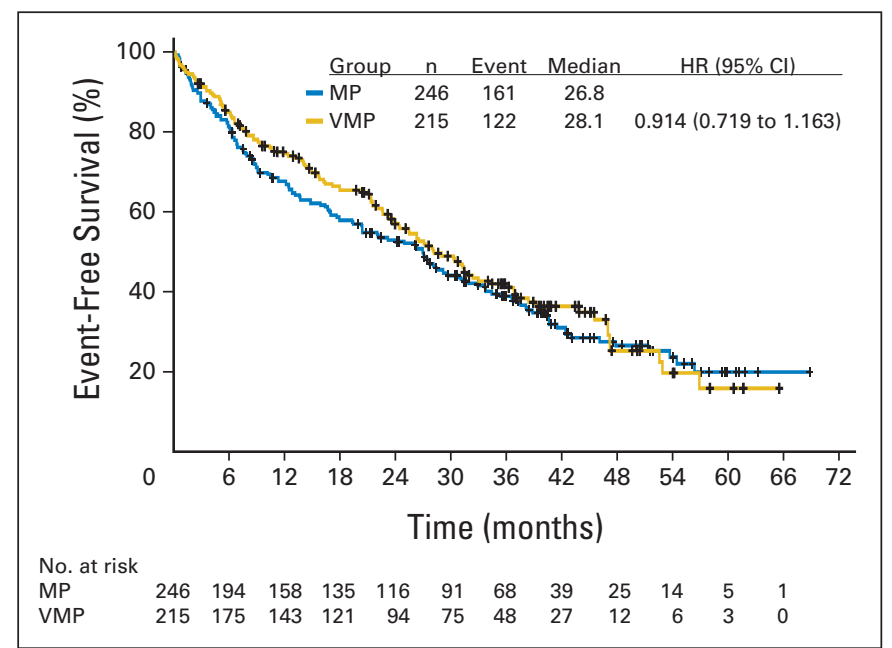

Fig 4. Analysis of survival from start of subsequent therapy in all randomly assigned patients who received subsequent therapy. HR, hazard ratio; MP, melphalan-prednisone; VMP, bortezomib-melphalan-prednisone.

\section{DISCUSSION}

The findings of this final analysis of the VISTA phase III trial demonstrate a persistent significant OS benefit with VMP versus MP. These data are highly robust because of the large patient population and lengthy follow-up and show that VMP resulted in a substantial longterm OS benefit versus MP, with a 13.3-month increase in the median. This benefit compares favorably with the 6.6-month increase in median OS (39.3 $v 32.7$ months) reported in a meta-analysis of six phase III trials of MP plus thalidomide (MPT) versus MP. ${ }^{19}$ The HR for OS in this meta-analysis was 0.83 ( $95 \% \mathrm{CI}, 0.73$ to $0.94 ; P=.004$ ), representing a $17 \%$ reduced risk of death with $\mathrm{MPT}^{19}$ compared with the 31\% reduced risk of death with VMP versus MP reported here. Notably, the median follow-up in seven individual studies of MPT versus MP ranges from 23 to 51.5 months, ${ }^{12-18}$ compared with the 60.1-month follow-up for the analysis reported here. In addition, it should be noted that the OS benefit observed in this trial was not due to a poor outcome with MP, since median OS with MP in this trial (43.1 months) was longer than median OS with MP in the MPT trial meta-analysis (32.7 months). The median OS observed with VMP (56.4 months) appears similar to that previously reported after longterm follow-up from studies of high-dose therapy and autologous stem-cell transplantation conducted in the 1990s and early 2000s (median, 4.0 to 5.7 years) ${ }^{37}$; however, as reviewed recently, it should be noted that results from transplantation studies have also significantly improved in the past decade with the combination of novel drugs (median of approximately 7 to 10 years). ${ }^{37}$

Importantly, the OS benefit with VMP versus MP was seen across multiple prespecified patient subgroups, including similar benefit in elderly (age $\geq 75$ years) and younger patients, and the HR in favor of VMP was generally consistent with that for the overall population, 


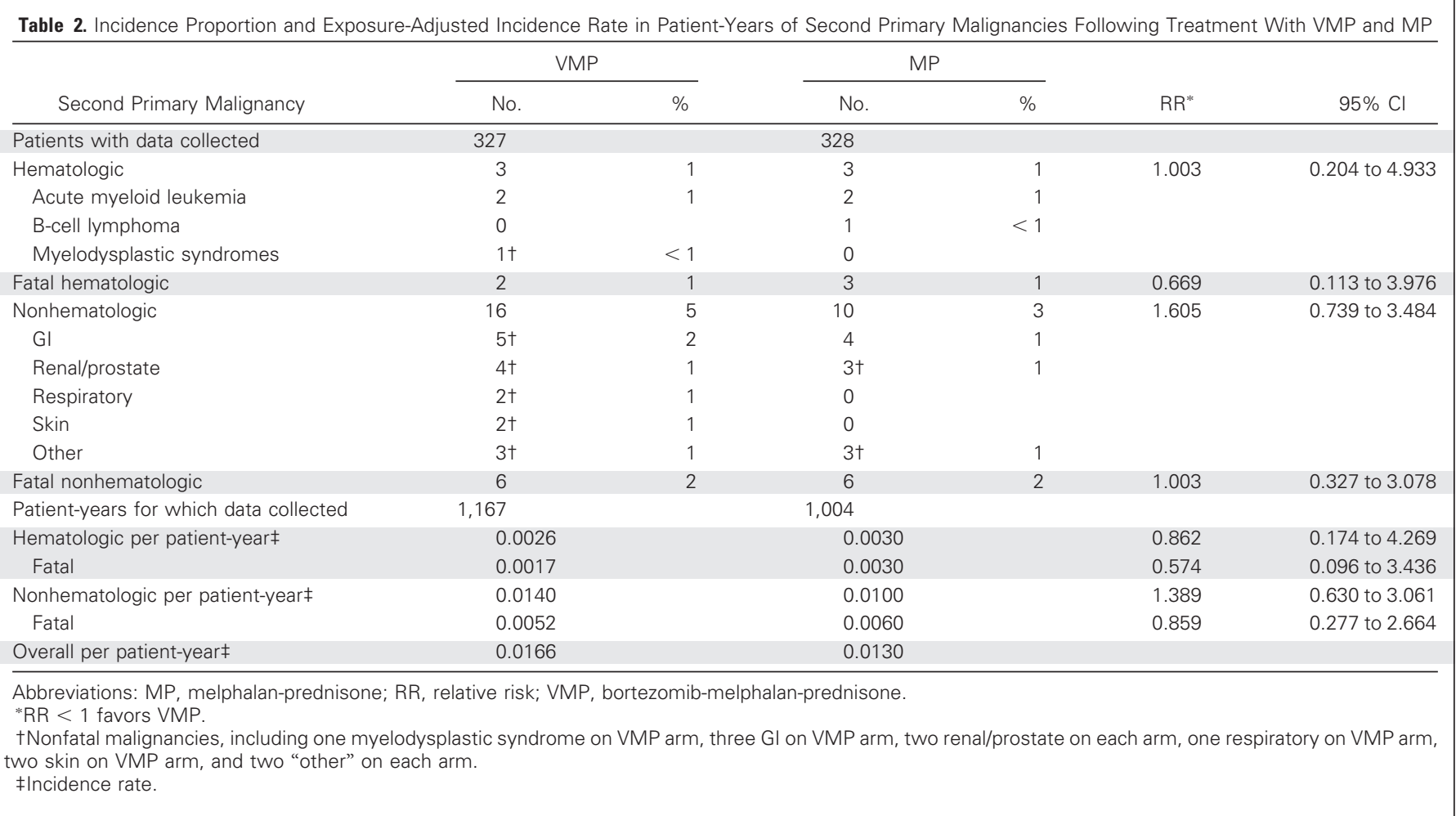

indicating the applicability of these findings to the broad MM population. However, there was an absence of OS benefit among the small subgroup of patients with documented high-risk cytogenetics (Fig 3), whereas bortezomib-based therapy has previously been shown to result in high response rates and promising long-term outcomes in such patients. ${ }^{10,11,38-47}$ The limited sample size prevents any meaningful conclusions from being drawn.

As reported for the previous analysis of VISTA, ${ }^{10} \mathrm{VMP}$ continued to provide a significant clinical benefit versus MP in terms of prolonged TTNT and TFI. TTP and PFS could not be updated this final analysis because they were based on central laboratory assessment and, because of the highly significant initial benefit observed for these end points, ${ }^{11}$ it was decided to stop central assessment following the initial analysis.

Survival from the start of subsequent therapy was similar between arms, indicating that VMP did not induce more resistant relapses. This finding is particularly notable because this analysis contained a bias in favor of MP-treated patients, because it excluded a higher proportion of VMP-treated patients who experienced most benefit (ie, those who had not yet required subsequent therapy and were thus most sensitive to therapy or had better prognosis). In addition, OS with VMP was significantly longer versus the treatment paradigm of first-line MP followed by salvage bortezomib (ie, MP patients who did receive, or could have received, bortezomib at relapse). Overall, these findings demonstrate the importance of a treatment paradigm of providing optimal first-line treatment, rather than reserving novel agents for salvage therapy.

To the best of our knowledge, this is the first paper reporting the incidence of second primary malignancies with bortezomib-based treatment. It is important to highlight that less than $5 \%$ of patients were lost to follow-up. With this thorough data collection, we identified no increased risk of second primary malignancies with VMP versus MP. Importantly, overall incidence rates in both arms (VMP, 0.017 and MP, 0.0130 per patient-year) were consistent with the background incidence rate of 0.019 for all cancers in the general US population age 65 to 74 years, as reported for 2004 to 2008 by the SEER Program. ${ }^{48}$ These data indicate that use of bortezomib for up to approximately 1 year does not add to the previously reported leukemogenic effect of melphalan, ${ }^{24,27,29}$ with the incidence rates of secondary hematologic malignancies low and similar in both the VMP and MP arms. Addition of lenalidomide to MP and use of maintenance lenalidomide until progression (median PFS, 31 months) has been suggested to result in a small increased risk of secondary leukemia compared with MP alone, although this may be associated with the presence of complex cytogenetics at baseline. ${ }^{20}$ However, the increased risk of secondary malignancies with lenalidomide maintenance, which has also been shown post-transplantation, ${ }^{28,31}$ is counterbalanced by the highly significant PFS benefit demonstrated, ${ }^{20,28,31}$ together with an OS benefit in one study. ${ }^{31}$ Moreover, incidence rates were low, with no increase seen, in another study of lenalidomide-based therapy in the first-line setting. ${ }^{34}$

In conclusion, initial treatment of patients with $\mathrm{MM}$ who are ineligible for transplantation with VMP results in a significant reduction in the risk of death compared with initial treatment with MP that is maintained after 5 years of follow-up and despite substantial use of salvage therapies based on novel agents. Furthermore, our exploratory analysis identified no emerging safety signal for second primary malignancies following treatment with VMP. 


\section{AUTHORS' DISCLOSURES OF POTENTIAL CONFLICTS} OF INTEREST

Although all authors completed the disclosure declaration, the following author(s) and/or an author's immediate family member(s) indicated a financial or other interest that is relevant to the subject matter under consideration in this article. Certain relationships marked with a " $U$ " are those for which no compensation was received; those relationships marked with a " $C$ " were compensated. For a detailed description of the disclosure categories, or for more information about ASCO's conflict of interest policy, please refer to the Author Disclosure Declaration and the Disclosures of Potential Conflicts of Interest section in Information for Contributors.

Employment or Leadership Position: Dixie-Lee Esseltine, Millennium Pharmaceuticals (C); Kevin Liu, Janssen R\&D (C); William Deraedt, Janssen R\&D (C); Andrew Cakana, Janssen R\&D (C); Helgi van de Velde, Janssen R\&D (C) Consultant or Advisory Role: Jesús F. San Miguel, Celgene (C), Janssen Pharmaceuticals (C), Millennium Pharmaceuticals (C); Meletios A. Dimopoulos, Ortho Biotech (C); Martin Kropff, Ortho Biotech (C), Celgene (C); Ivan Spicka, Janssen-Cilag Czech Republic (U); Antonio Palumbo, Celgene (C), Janssen-Cilag (C); Anna Dmoszynska, Mundipharma (C), Novartis Oncology (C); Michel Delforge, Janssen Pharmaceuticals (C), Celgene (C); Maria-Victoria Mateos, Janssen Pharmaceuticals (C), Millennium Pharmaceuticals (C); Kenneth C. Anderson, Celgene

(C), Millennium Pharmaceuticals (C); Paul G. Richardson, Celgene (C), Millennium Pharmaceuticals (C), Janssen Pharmaceuticals (C) Stock Ownership: Dixie-Lee Esseltine, Millennium Pharmaceuticals, Johnson \& Johnson; Kevin Liu, Johnson \& Johnson, Merck; William Deraedt, Johnson \& Johnson; Andrew Cakana, Johnson \& Johnson; Helgi van de Velde, Johnson \& Johnson Honoraria: Jesús F. San Miguel, Celgene, Janssen Pharmaceuticals, Millennium Pharmaceuticals; Meletios A. Dimopoulos, Ortho Biotech, Millennium Pharmaceuticals; Ofer Shpilberg, Janssen Pharmaceuticals; Martin Kropff, Celgene, Ortho Biotech; Ivan Spicka, Janssen-Cilag; Maria Teresa Petrucci,
Janssen-Cilag, Celgene; Antonio Palumbo, Celgene, Janssen-Cilag, Merck, Amgen, Bristol-Myers Squibb, Millennium Pharmaceuticals, Onyx Pharmaceuticals; Anna Dmoszynska, Millennium Pharmaceuticals, Janssen Pharmaceuticals; Michel Delforge, Janssen Pharmaceuticals, Celgene; Maria-Victoria Mateos, Janssen Pharmaceuticals, Millennium Pharmaceuticals; Kenneth C. Anderson, Celgene, Millennium Pharmaceuticals Research Funding: Ofer Shpilberg, Janssen Pharmaceuticals Expert Testimony: None Other Remuneration: Ivan Spicka, Janssen-Cilag

\section{AUTHOR CONTRIBUTIONS}

Conception and design: Jesús F. San Miguel, Meletios A. Dimopoulos, Antonio Palumbo, Maria-Victoria Mateos, Kenneth C. Anderson, Dixie-Lee Esseltine, Kevin Liu, Helgi van de Velde, Paul G. Richardson Provision of study materials or patients: Jesús F. San Miguel, Rudolf Schlag, Nuriet K. Khuageva, Meletios A. Dimopoulos, Ofer Shpilberg, Martin Kropff, Ivan Spicka, Maria Teresa Petrucci, Antonio Palumbo, Olga S. Samoilova, Anna Dmoszynska, Kudrat M. Abdulkadyrov, Michel Delforge, Bin Jiang, Maria-Victoria Mateos, Paul G. Richardson Collection and assembly of data: Jesús F. San Miguel, Rudolf Schlag, Nuriet K. Khuageva, Meletios A. Dimopoulos, Ofer Shpilberg, Martin Kropff, Ivan Spicka, Maria Teresa Petrucci, Antonio Palumbo, Olga S. Samoilova, Anna Dmoszynska, Kudrat M. Abdulkadyrov, Michel Delforge, Bin Jiang, Maria-Victoria Mateos, Kenneth C. Anderson, Kevin Liu, William Deraedt, Andrew Cakana, Helgi van de Velde, Paul G. Richardson

Data analysis and interpretation: Jesús F. San Miguel, Meletios A. Dimopoulos, Ofer Shpilberg, Michel Delforge, Maria-Victoria Mateos, Kevin Liu, William Deraedt, Andrew Cakana, Helgi van de Velde, Paul G. Richardson Manuscript writing: All authors Final approval of manuscript: All authors

\section{REFERENCES}

1. Harousseau JL: Optimising patient outcomes in myeloma. Cancer Treat Rev 36:S33-S35, 2010 (suppl 2)

2. Richardson PG, Laubach J, Mitsiades CS, et al: Managing multiple myeloma: The emerging role of novel therapies and adapting combination treatment for higher risk settings. $\mathrm{Br} J$ Haematol 10.1111/j.1365-2141.2011.08791.x [epub ahead of print on July 7, 2011]

3. Anderson KC, Kyle RA, Rajkumar SV, et al: Clinically relevant end points and new drug approvals for myeloma. Leukemia 22:231-239, 2008

4. Lonial S, Mitsiades CS, Richardson PG: Treatment options for relapsed and refractory multiple myeloma. Clin Cancer Res 17:1264-1277, 2011

5. Kumar SK, Rajkumar SV, Dispenzieri A, et al: Improved survival in multiple myeloma and the impact of novel therapies. Blood 111:2516-2520, 2008

6. Brenner H, Gondos A, Pulte D: Recent major improvement in long-term survival of younger patients with multiple myeloma. Blood 111:25212526, 2008

7. Brenner H, Gondos A, Pulte D: Expected long-term survival of patients diagnosed with multiple myeloma in 2006-2010. Haematologica 94:270275, 2009

8. Kastritis $E$, Zervas $K$, Symeonidis A, et al: Improved survival of patients with multiple myeloma after the introduction of novel agents and the appli- cability of the International Staging System (ISS): An analysis of the Greek Myeloma Study Group (GMSG). Leukemia 23:1152-1157, 2009

9. Venner CP, Connors JM, Sutherland HJ, et al: Novel agents improve survival of transplant patients with multiple myeloma including those with highrisk disease defined by early relapse ( $<12$ months). Leuk Lymphoma 52:34-41, 2011

10. Mateos MV, Richardson PG, Schlag R, et al: Bortezomib plus melphalan and prednisone compared with melphalan and prednisone in previously untreated multiple myeloma: Updated follow-up and impact of subsequent therapy in the phase III VISTA trial. J Clin Oncol 28:2259-2266, 2010

11. San Miguel JF, Schlag R, Khuageva NK, et al: Bortezomib plus melphalan and prednisone for initial treatment of multiple myeloma. $N$ Engl J Med 359:906-917, 2008

12. Beksac M, Haznedar R, Firatli-Tuglular T, et al: Addition of thalidomide to oral melphalan/prednisone in patients with multiple myeloma not eligible for transplantation: Results of a randomized trial from the Turkish Myeloma Study Group. Eur J Haematol 86:16-22, 2011

13. Facon T, Mary JY, Hulin C, et al: Melphalan and prednisone plus thalidomide versus melphalan and prednisone alone or reduced-intensity autologous stem cell transplantation in elderly patients with multiple myeloma (IFM 99-06): A randomised trial. Lancet 370:1209-1218, 2007

14. Hulin C, Facon T, Rodon $P$, et al: Efficacy of melphalan and prednisone plus thalidomide in patients older than 75 years with newly diagnosed multiple myeloma: IFM 01/01 trial. J Clin Oncol 27:3664-3670, 2009

15. Palumbo A, Bringhen $S$, Liberati $A M$, et al: Oral melphalan, prednisone, and thalidomide in elderly patients with multiple myeloma: Updated results of a randomized controlled trial. Blood 112: 3107-3114, 2008

16. Waage A, Gimsing $P$, Fayers $P$, et al: Melphalan and prednisone plus thalidomide or placebo in elderly patients with multiple myeloma. Blood 116:1405-1412, 2010

17. Wijermans $P$, Schaafsma $M$, Termorshuizen F, et al: Phase III study of the value of thalidomide added to melphalan plus prednisone in elderly patients with newly diagnosed multiple myeloma: The HOVON 49 Study. J Clin Oncol 28:3160-3166, 2010

18. Sacchi S, Marcheselli R, Lazzaro A, et al: A randomized trial with melphalan and prednisone versus melphalan and prednisone plus thalidomide in newly diagnosed multiple myeloma patients not eligible for autologous stem cell transplant. Leuk Lymphoma 52:1942-1948, 2011

19. Fayers PM, Palumbo A, Hulin C, et al: Thalidomide for previously untreated elderly patients with multiple myeloma: Meta-analysis of 1685 individual patient data from 6 randomized clinical trials. Blood 118:1239-1247, 2011

20. Palumbo A, Hajek R, Delforge $M$, et al: Continuous lenalidomide treatment for newly diagnosed multiple myeloma. N Engl J Med 366:1759-1769, 2012

21. Palumbo A, Bringhen $S$, Zweegman $S$, et al: Secondary malignancies in elderly myeloma patients. Haematologica 96:S24, 2011 (suppl; abstr S24) 
22. Dong C, Hemminki K: Second primary neoplasms among 53159 haematolymphoproliferative malignancy patients in Sweden, 1958-1996: A search for common mechanisms. Br J Cancer 85: 997-1005, 2001

23. Hasskarl J, Ihorst G, De Pasquale D, et al: Association of multiple myeloma with different neoplasms: Systematic analysis in consecutive patients with myeloma. Leuk Lymphoma 52:247-259, 2011

24. Bergsagel DE, Bailey AJ, Langley GR, et al: The chemotherapy on plasma-cell myeloma and the incidence of acute leukemia. N Engl J Med 301:743748, 1979

25. Mailankody S, Pfeiffer RM, Kristinsson SY, et al: Risk of acute myeloid leukemia and myelodysplastic syndromes after multiple myeloma and its precursor disease (MGUS). Blood 118:4086-4092, 2011

26. Dores G, Cote TR, Travis LB: New malignancies following Hodgkin lymphoma, non-Hodgkin lymphoma, and myeloma, in Curtis RE, Freedman DM, Ron E, et al (eds): New Malignancies Among Cancer Survivors: SEER Cancer Registries, 19732000. Bethesda, MD, National Cancer Institute, NIH publication 05-5302, 2006, pp 397-435

27. [No authors listed]: Acute leukaemia and other secondary neoplasms in patients treated with conventional chemotherapy for multiple myeloma: A Finnish Leukaemia Group study. Eur J Haemato 65:123-127, 2000

28. Attal M, Lauwers-Cances $V$, Marit $G$, et al: Lenalidomide maintenance after stem-cell transplantation for multiple myeloma. N Engl J Med 366:1782-1791, 2012

29. Cuzick J, Erskine S, Edelman D, et al: A comparison of the incidence of the myelodysplastic syndrome and acute myeloid leukaemia following melphalan and cyclophosphamide treatment for myelomatosis: A report to the Medical Research Council's Working Party on Leukaemia in Adults. $\mathrm{Br} J$ Cancer 55:523-529, 1987

30. Majhail NS: Old and new cancers after hematopoietic-cell transplantation. Hematology Am Soc Hematol Educ Program 2008:142-149

31. McCarthy PL, Owzar K, Hofmeister CC, et al: Lenalidomide after stem-cell transplantation for multiple myeloma. N Engl J Med 366:1770-1781, 2012
32. Pedersen-Bjergaard J, Andersen MK, Christiansen DH: Therapy-related acute myeloid leukemia and myelodysplasia after high-dose chemotherapy and autologous stem cell transplantation. Blood 95:3273-3279, 2000

33. Dimopoulos MA, Richardson PG, Brandenburg N, et al: A review of second primary malignancy in patients with relapsed or refractory multiple myeloma treated with lenalidomide. Blood 119:2764-2767, 2012

34. Rossi AC, Mark TM, Jayabalan D, et al: Incidence of second primary malignancies (SPM) after 6-years follow-up of continuous lenalidomide in firstline treatment of multiple myeloma (MM). J Clin Oncol 29:506s, 2011 (suppl; abstr 8008)

35. Bladé J, Samson D, Reece D, et al: Criteria for evaluating disease response and progression in patients with multiple myeloma treated by high-dose therapy and haemopoietic stem cell transplantation: Myeloma Subcommittee of the EBMT-European Group for Blood and Marrow Transplant. $\mathrm{Br} J$ Haematol 102:1115-1123, 1998

36. Greipp PR, San Miguel J, Durie BG, et al: International staging system for multiple myeloma. J Clin Oncol 23:3412-3420, 2005

37. Barlogie B, Attal M, Crowley J, et al: Longterm follow-up of autotransplantation trials for multiple myeloma: Update of protocols conducted by the Intergroupe Francophone du Myelome, Southwest Oncology Group, and University of Arkansas for Medical Sciences. J Clin Oncol 28:1209-1214, 2010

38. Avet-Loiseau $H$, Leleu $X$, Roussel $M$, et al: Bortezomib plus dexamethasone induction improves outcome of patients with $\mathrm{t}(4 ; 14)$ myeloma but not outcome of patients with del(17p). J Clin Oncol 28:4630-4634, 2010

39. Cavo M, Bringhen S, Terragna $C$, et al: Bortezomib-based induction treatments improve outcomes of newly diagnosed multiple myeloma patients with high-risk cytogenetic abnormalities. Blood 116:342a-343a, 2010 (suppl; abstr 781)

40. Cavo M, Tacchetti P, Patriarca F, et al: Bortezomib with thalidomide plus dexamethasone compared with thalidomide plus dexamethasone as induction therapy before, and consolidation therapy after, double autologous stem-cell transplantation in newly diagnosed multiple myeloma: A randomised phase 3 study. Lancet 376:2075-2085, 2010

41. Einsele $H$, Liebisch $P$, Langer $C$, et al: Velcade, intravenous cyclophosphamide and dexamethasone (VCD) induction for previously untreated multiple myeloma (German DSMM Xla trial). Blood 114:59a60a, 2009 (suppl; abstr 131)

42. Goldschmidt $H$, Neben $K$, Bertsch $U$, et al: Bortezomib-based induction therapy followed by autologous stem cell transplantation and maintenance therapy with bortezomib improves outcome in myeloma patients with gain $1 \mathrm{q} 21$ and $t(4 ; 14)$ : A subgroup analysis of the HOVON-65/GMMG-HD4 trial. Blood 116:138a-139a, 2010 (suppl; abstr 305)

43. Harousseau JL, Attal M, Avet-Loiseau H, et al: Bortezomib plus dexamethasone is superior to vincristine plus doxorubicin plus dexamethasone as induction treatment prior to autologous stem-cell transplantation in newly diagnosed multiple myeloma: Results of the IFM 2005-01 phase III trial. J Clin Oncol 28:4621-4629, 2010

44. Mateos MV, Hernández JM, Hernández MT, et al: Bortezomib plus melphalan and prednisone in elderly untreated patients with multiple myeloma: Updated time-to-events results and prognostic factors for time to progression. Haematologica 93:560565, 2008

45. Mateos MV, Gutiérrez NC, Martín-Ramos ML, et al: Outcome according to cytogenetic abnormalities and DNA ploidy in myeloma patients receiving short induction with weekly bortezomib followed by maintenance. Blood 118:4547-4553, 2011

46. Richardson PG, Weller E, Lonial S, et al: Lenalidomide, bortezomib, and dexamethasone combination therapy in patients with newly diagnosed multiple myeloma. Blood 116:679-686, 2010

47. Reece D, Rodriguez GP, Szwajcer D, et al: Phase II trial of bortezomib-based therapy without ASCT in newly diagnosed patients with $t(4 ; 14)$ multiple myeloma. Haematologica 96:S95, 2011 (suppl 1; abstr P-220)

48. Howlader N, Noone AM, Krapcho M, et al: SEER Cancer Statistics Review, 1975-2008. National Cancer Institute, Bethesda, MD, 2011. http://seer.cancer.gov/ csr/1975_2008/browse_csr.php? section $=2 \&$ page $=$ sect_02_table.07.html

\section{Affiliations}

Jesús F. San Miguel and Maria-Victoria Mateos, Hospital Universitario Salamanca, Instituto de Investigación Biomédica de Salamanca; Instituto de Biología Molecular y Celular del Cáncer, Universidad de Salamanca-Consejo Superior de Investigaciones Cientificas, Salamanca, Spain; Rudolf Schlag, Praxisklinik Dr. Schlag, Würzburg; Martin Kropff, University of Münster, Münster, Germany; Nuriet K. Khuageva, SP Botkin Moscow City Clinical Hospital, Moscow; Olga S. Samoilova, Nizhnii Novgorod Region Clinical Hospital, Nizhnii Novgorod; Kudrat M. Abdulkadyrov, St Petersburg Clinical Research Institute of Hematology and Transfusiology, St Petersburg, Russia; Meletios A. Dimopoulos, University of Athens School of Medicine, Athens, Greece; Ofer Shpilberg, Rabin Medical Center, Petah-Tiqva, Israel; Ivan Spicka, Charles University Prague, Prague, Czech Republic; Maria Teresa Petrucci, University La Sapienza, Rome; Antonio Palumbo, Universita di Torino, Torino, Italy; Anna Dmoszynska, Medical University of Lublin, Lublin, Poland; Michel Delforge, Myeloma Study Group, Belgian Hematological Society, Brussels; William Deraedt and Helgi van de Velde, Janssen Research \& Development, Beerse, Belgium; Bin Jiang, People's Hospital, Peking University, Beijing, China; Kenneth C. Anderson and Paul G. Richardson, Dana-Farber Cancer Institute, Boston; Dixie-Lee Esseltine, Millennium Pharmaceuticals, Cambridge, MA; Kevin Liu, Janssen Research \& Development, Raritan, NJ; and Andrew Cakana, Janssen Research \& Development, High Wycombe, United Kingdom. 